\title{
Technical note: Estimation of feed intake while grazing using a wireless system requiring no halter
}

\author{
K. Umemura, ${ }^{\star 1}$ T. Wanaka, $†$ and T. Ueno† \\ *National Agricultural Research Center for Hokkaido Region, Toyohira, Sapporo, 062-8555, Japan \\ †Panasonic Electric Works Co., Ltd., Kadoma, Osaka, 571-8686, Japan
}

\begin{abstract}
A simple, compact bite counter was used to record dairy cow jaw movements. This information was used to estimate feed intake. The device is composed of a pendulum, a microcontroller, and a transmitter attached to a collar. The microcontroller memory can store the number of bites over 10-min intervals for up to $3 \mathrm{mo}$ and has a battery life of more than $1 \mathrm{yr}$. The number of bites measured by personal observation, and the values reported by the counter were compared for 5 multiparous, nonlactating Holstein cows. The correlation was linear with an $\mathrm{R}^{2}$ value of 0.9 , unaffected by rumination, and little affected by walking. The collar system avoided the problems often experienced with counters attached to halters. The utility of the bite counter recordings in estimating intake was tested using 8 multiparous lactating cows. The slopes of the regression lines relating the number of bites to feed intake were dependent on the level of available pasture mass (120 or $190 \mathrm{~g}$ standing dry matter $/ \mathrm{m}^{2}$ ). The feed intake could be estimated by applying linear regression to the number of bite counts versus pasture disappearance. In both cases the $\mathrm{R}^{2}$ values of the regression lines were $>0.7$. Although the counter recorded jaw movements during grazing when the head was down, it did not record rumination or mastication when the head was raised because the counter/collar did not contact the jaw in this position. The bite counters were easy to attach to the cows using the collar and could be used effectively by farmers and researchers.
\end{abstract}

Key words: feed intake, grazing behavior, halter, bite counter

Because feed intake is difficult to measure, farmers are often concerned that their stocks are not being appropriately fed (Holmes and Wilson, 1984). For research purposes, feed intake and grazing time are important in the study of animal production, pasture production, and grazing management (Allden, 1962).

Received February 3, 2008.

Accepted October 24, 2008.

${ }^{1}$ Corresponding author: umemura@affrc.go.jp
The number of jaw movements during grazing was an indirect indicator of individual feed intake (Chacon et al., 1976). Several automatic devices requiring a halter were developed that measure the jaw movements of grazing animals (Forbes, 1988; Rutter et al., 1997), but not requiring a halter would be advantageous for cost and convenience.

A system that counts the jaw movements of grazing animals using a bite counter attached to a collar is described. The system was validated by determining whether or not the bite counter was measuring actual bites, then determining whether feed intake could be accurately estimated based on the bite counter recordings.

Jaw movements were recorded using a system developed by Panasonic Electric Works Co. Ltd. (Kadoma, Osaka, Japan) and consisting of an 8-bit microcontroller (PIC16LF873), a 64-kB nonvolatile memory, and a transmitter with an internal antenna (Figure 1a). The memory was large enough to store the number of bites counted over 10-min intervals for up to $3 \mathrm{mo}$, and the battery (3.6 V, 2,000 mAh, size: AA, TL-2100, Tadiran, Kiryat Ekron, Israel) had a life of more than $1 \mathrm{yr}$. These specifications were established to ensure efficient data acquisition in fields located far from a laboratory. To achieve low power consumption, jaw movement was sensed using a pendulum for a pedometer equipped with a small magnet in proximity to a reed switch (Figure 1b). The pendulum was used as a digital accelerometer of backward and forward motion in the longitudinal axis of the body. The wireless data transmission employed amplitude-shift keying, a form of modulation that represents digital data as variations in the amplitude of a carrier wave. The unit was contained in a waterproof plastic case $(105 \times 80 \times 46 \mathrm{~mm})$ and weighed $354 \mathrm{~g}$.

The data receiver for the bite recorder consisted of a transceiver and dipole antenna powered from a personal computer. The maximum transmission range was about $10 \mathrm{~m}$, and the data were manually downloaded when needed. The wireless connection enabled data acquisition without removing the counter, facilitating regular data collection to assist farmers in feed management. 
A.

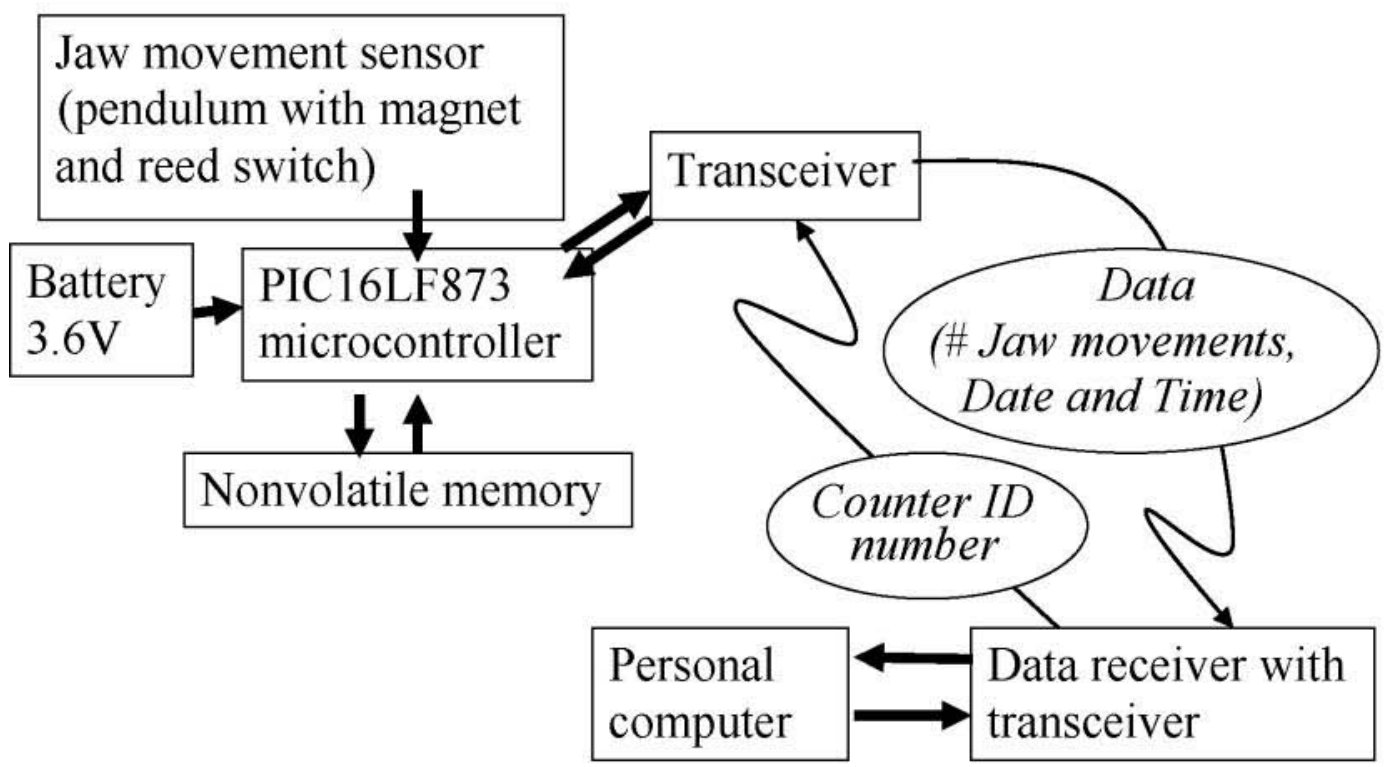

B.
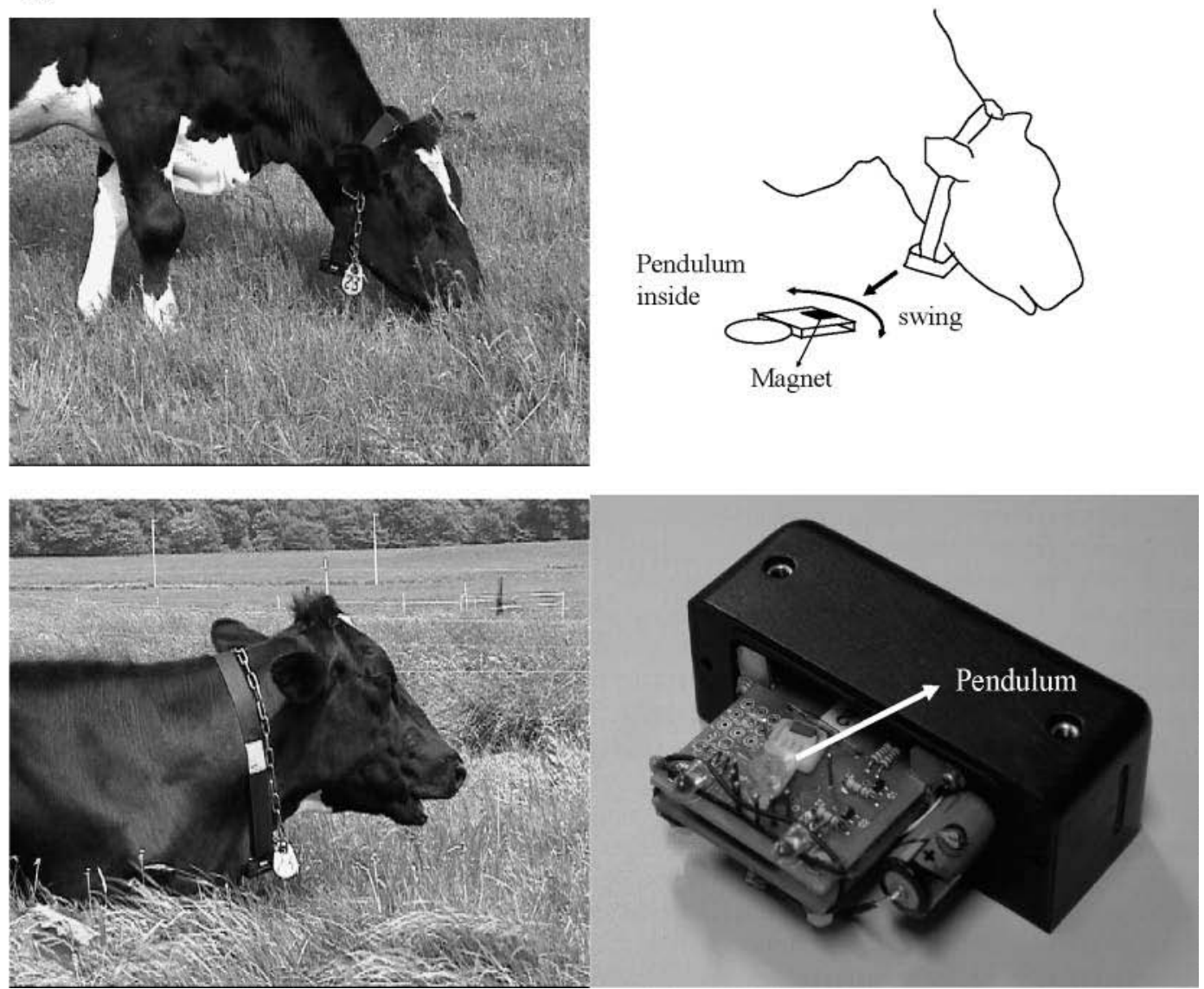

Figure 1. A. Diagramatic illustration of the bite counter data access process. B. The bite counter suspended from the collar rests against the jaw during grazing (above left), but not during rumination (below left). A pendulum with a small magnet was used as a sensor of jaw movement while the cow's head was in the down position (above right). An inside view of bite counter (below right). 


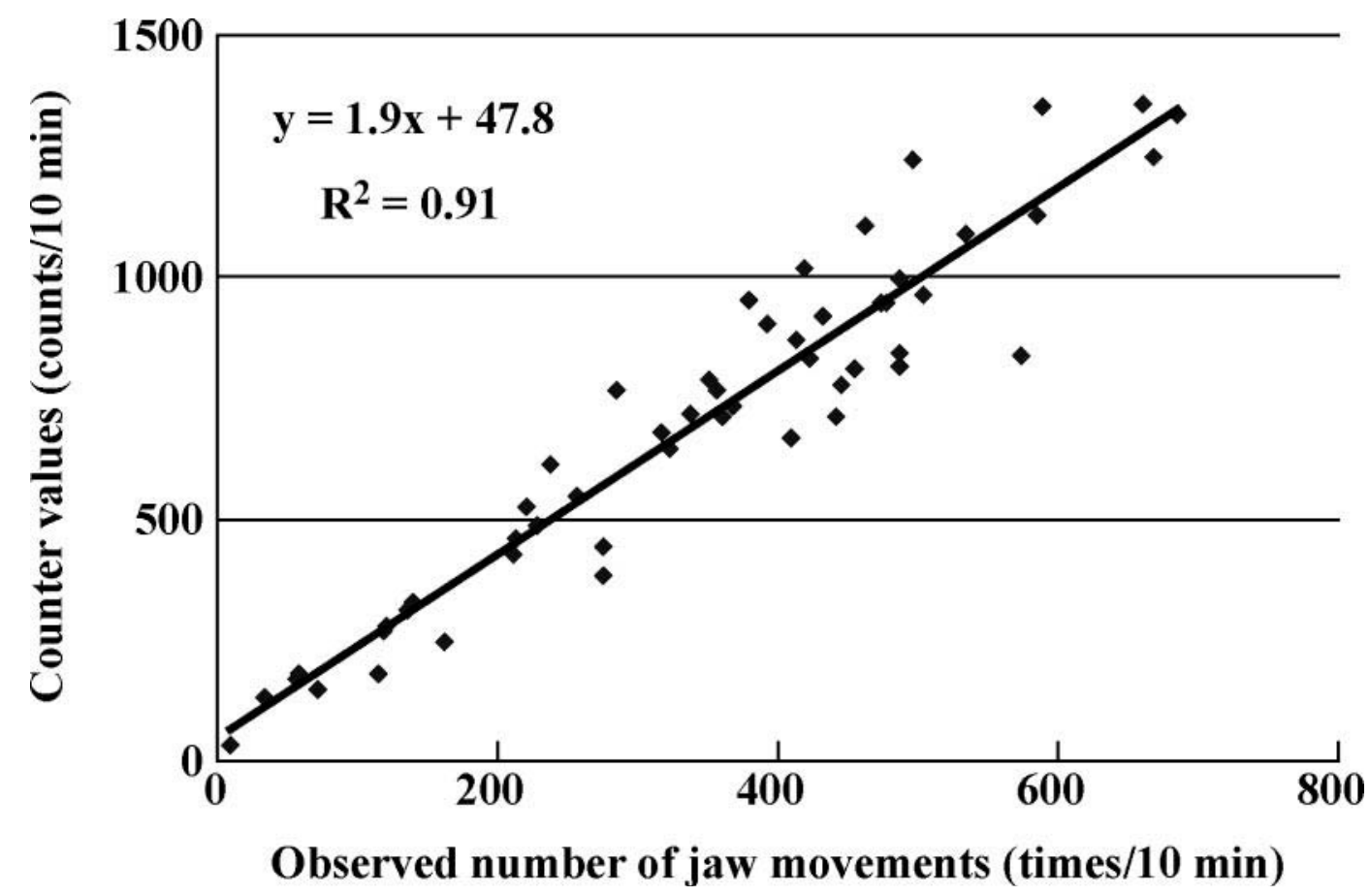

Figure 2. The relationship between manual jaw counts and counts made by jaw movement counter.

A field trial was carried out to test the ability of the counter to record the biting jaw movements of grazing cows. Five multiparous, nonlactating Holstein cows were grazed on a 0.1-ha experimental plot consisting of meadow fescue and white clover. Each animal was fitted with a counter. The animals had previous experience wearing the collar with the counter. Grazing jaw movements were counted over a 10 -min period a total of 52 times (10 to 16 times/cow) over 13 d. A cow would typically be observed once or twice daily. Data were downloaded after every observation.

The bite counters were easy to attach to the cows using the collar and could be used effectively by farmers and researchers. The collar system avoided the problems often experienced with halter-mounted counters. The relationship between the number of bites measured by observation and by the counter was linear ( $F$-test, $P$ $<0.001$; Figure 2).

Rumination behavior was recorded using the same procedure. On 5 separate days, a cow was observed 4 times during the day for a total of 20 observations. During rumination, the mean rate of jaw movement was 604 times/10 min and the mean counter value was 0.45 counts/10 min because the counter was not in contact with the jaw while the head was raised (Figure 1b).

Steps were counted while cows were moved from the barn to the pasture to determine if walking movements were recorded by the bite counter. The mean counter value obtained from 5 cows while walking was low (36.5 counts per $5 \mathrm{~min}, \mathrm{n}=10)$ in spite of the number of steps taken (mean 328.5 steps per 5 min, $\mathrm{n}=10$ ). Each cow was observed twice over $10 \mathrm{~d}$.

The number of counts recorded during rumination was $0.0007 \%$ of the number of jaw movements and while walking was $11.1 \%$ of the number of steps. These were very low in relation to the number of bite counts recorded over 10-min intervals during grazing (Figure 3 ), and the recorded bite counts resulted almost entirely from grazing activity.

The utility of the bite counter recordings in estimating feed intake was tested using 8 multiparous lactating cows. The cows were grazed in individual, adjacent meadow fescue and white clover paddocks with a mean herbage allowance of more than $5 \mathrm{~kg}$ of standing DM/d per $100 \mathrm{~kg}$ of BW per cow. The cow BW was $566 \pm$ $32 \mathrm{~kg}$. The DM in each paddock was measured with a rising plate meter (RPM; Reeves, 1996) before grazing and 4,8 , and $22 \mathrm{~h}$ from the start of grazing to calculate the rate of DM consumption during grazing. These 8 paddock observations were conducted at 1 time. The RPM was calibrated to measure the available DM above a 5 -cm stubble height, using eight $1-\mathrm{m}^{2}$ quadrants. The experiments were conducted at 2 levels of available DM, 120 and $190 \mathrm{~g}$ of $\mathrm{DM} / \mathrm{m}^{2}$, corresponding to 21- and 28-cm sward heights in September and June, respectively. The equations for estimation of DM with RPM were $\mathrm{y}=11.523 \mathrm{x}-42.528\left(\mathrm{y}=\mathrm{g}\right.$ of $\mathrm{DM} / \mathrm{m}^{2}, \mathrm{x}$ $=$ reading of RPM) for September and $\mathrm{y}=9.270 \mathrm{x}-$ 


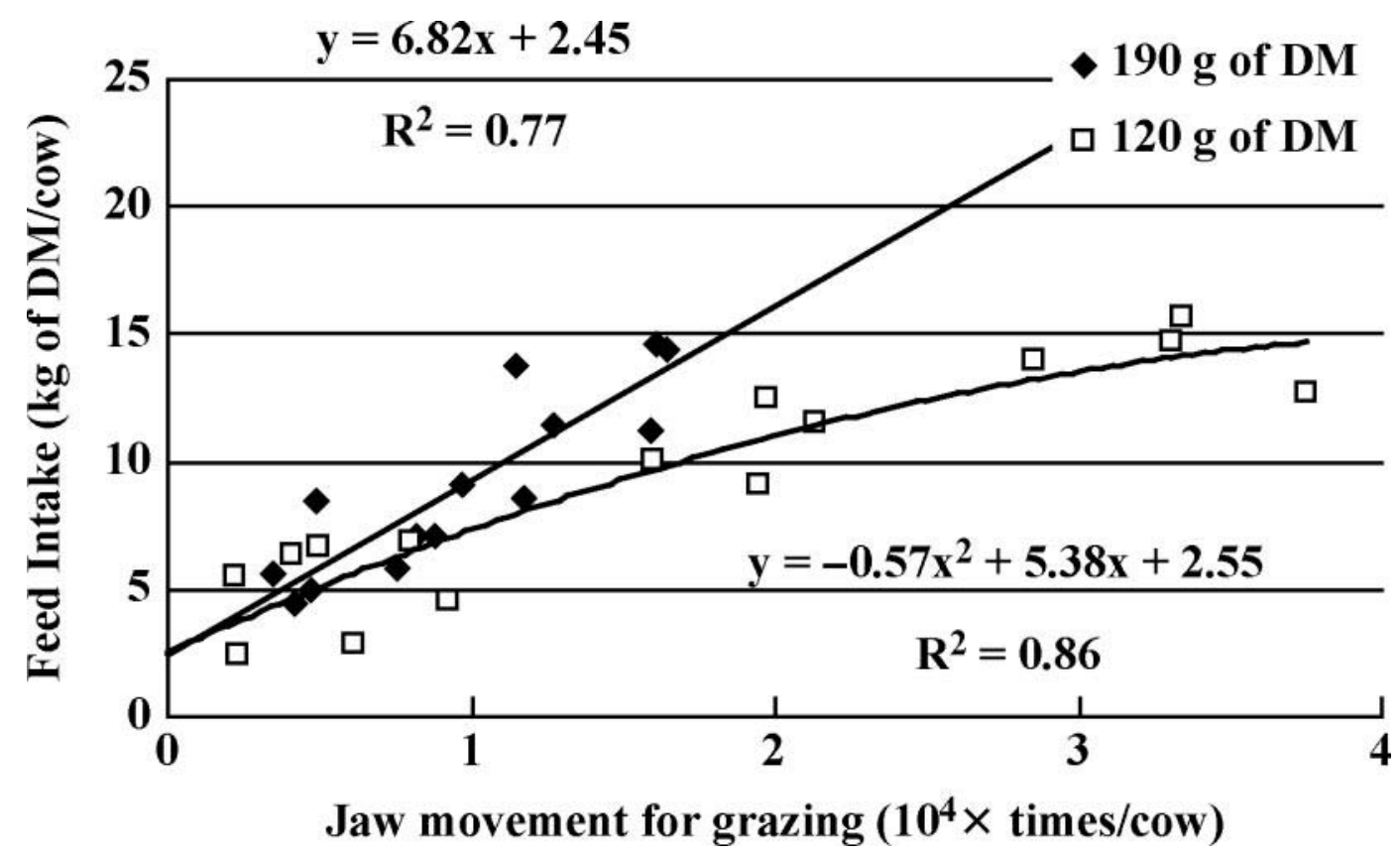

Figure 3. The relationship between bites for grazing and feed intake estimated by standing DM disappearance during grazing (120 g of DM/ $\mathrm{m}^{2}$ polynomial function; $190 \mathrm{~g}$ of $\mathrm{DM} / \mathrm{m}^{2}$ linear function).

5.588 for June. The $120 \mathrm{~g}$ of DM level was the result of mowing the pasture. Differences between the number of jaw movements and the feed intake were assessed by regression analysis.

Bite counts were converted to true (observed) bites (Figure 2) because the counter values were 1.9 times the number actually observed. This was probably due to inertia of the plastic case from the weight that made exact bounds at each head movement due to prehension. This correction enabled a comparison with previously published data.

Difference of the regression lines $(F$-test, $P<0.001)$ relating the number of bites to feed intake (pasture DM disappearance) on the 2 levels of available pasture mass (Figure 3) suggest bite size increases on the longer pasture (Forbes, 1988). In both cases the $\mathrm{R}^{2}$ values of the regression lines were $>0.7$, suggesting that intake can be predicted from bite counts using this simple counter system. Cows grazing the low pasture mass appeared to reach a plateau of DM intake as the bite count increased. This is consistent with a declining bite size with increasing time on the same pasture and declining pasture availability. On the longer pasture, intake increased linearly with increasing number of bites even though the residual herbage allowance was almost the same as the shorter pasture at the end of the experiment (Chacon et al., 1976; Forbes, 1988; Gibb et al., 1997). Although this system (unlike the conventional equipment) could not distinguish between prehensile bites (when herbage is severed and gathered into the mouth) and mastication (when previously prehended material is manipulated and swallowed with the head down; Rutter, 2000), the lines relating number of bites to feed intake were highly correlated. This was probably due to detecting head movements according to prehension. Chambers et al. (1981) suggested that recording not only jaw movements, but also head movements, was reliable for estimating bite size. It may not be necessary to distinguish between bite types to estimate feed intake.

Though the counter recorded jaw movements during grazing when the head was down, it did not record rumination or mastication when the head was raised because the counter/collar did not contact the jaw in this position. With some experience, the collars are easy to attach and use. The system is amenable to measuring indoor eating behavior, whether the cow is free or in a stanchion stall, because the counter is in contact with the jaw while the head is down during eating. This technology could be incorporated into existing collar-based transponders that are already used widely in dairy cows.

\section{ACKNOWLEDGMENTS}

The authors gratefully acknowledge the helpful discussions with Keith Betteridge (Agresearch Grasslands, Palmerston North, New Zealand), Mary H. Meyer 
(Minnesota Landscape Arboretum, Chaska, MN), and Lawrence D. Muller (professor emeritus of dairy science, Penn State University, University Park, PA).

\section{REFERENCES}

Allden, W. G. 1962. Rate of herbage intake and grazing time in relation to herbage availability. Proc. Aust. Soc. Anim. Prod. 4:163-171.

Chacon, E., T. H. Stobbs, and R. L. Sandland. 1976. Estimation of herbage consumption by grazing cattle using measurements of eating behaviour. J. Br. Grassl. Soc. 31:81-87.

Chambers, A. R. M., J. Hodgson, and J. A. Milne. 1981. The development and use of equipment for the automatic recording of ingestive behaviour in sheep and cattle. Grass Forage Sci. 36:97105 .

Forbes, T. D. A. 1988. Researching the plant-animal interface: The investigation of ingestive behavior in grazing animals. J. Anim. Sci. 66:2369-2379.
Gibb, M. J., C. A. Huckle, R. Nuthall, and A. J. Rook. 1997. Effect of sward surface height on intake and grazing behaviour by lactating Holstein Friesian cows. Grass Forage Sci. 52:309-321.

Holmes, C. W., and G. F. Wilson. 1984. Milk production from pasture. Page 24 in Feeding herd: Feed requirements and feeding levels. Butterworths of New Zealand (Ltd.), Wellington, New Zealand.

Reeves, M. W., J. Fulkerson, R. C. Kellaway, and H. Dove. 1996. A comparison of three techniques to determine the herbage intake of dairy cows grazing kikuyu (Pennisetum clandestinum) pasture. Aust. J. Exp. Agric. 36:23-30.

Rutter, S. M. 2000. Grazing: A program to analyze recordings of the jaw movements of ruminants. Behav. Res. Methods Instrum. Comput. 32:86-92.

Rutter, S. M., R. A. Champion, and P. D. Penning. 1997. An automatic system to record foraging behaviour in free-ranging ruminants. Appl. Anim. Behav. Sci. 54:185-195. 